\title{
Utilization of Starink Approach and Avrami Theory to Evaluate the Kinetic Parameters of the Pyrolysis of Olive Mill Solid Waste and Olive Mill Wastewater
}

\section{Guida $M Y^{1,3 *}$, Bouaik $H^{1}$, El Mouden $L^{1}$, Moubarik $A^{1}$, Aboulkas $A^{1,2}$, El harfi $K^{1,2}$ and Hannioui $A^{3}$}

${ }^{1}$ Interdisciplinary Research Laboratory of Science and Technology, Faculty of Polydisciplinary Beni Mellal, University Sultan Moulay Slimane, BP 592, 23000 Beni Mellal, Morocco

${ }^{2}$ Research Laboratory on the Reactivity of Materials and Processes Optimization "REMATOP", Department of Chemistry, Faculty of Science Semlalia, Cadi Ayyad University, BP 2390, 40001 Marrakech, Morocco

${ }^{3}$ Organic Chemistry and Analytical Laboratory, Faculty of Science and Technology of Beni Mellal, University Sultan Moulay Slimane, BP 523,23000 Beni Mellal, Morocco

\begin{abstract}
In this study, the thermal behavior of two olive mill wastes samples such as olive mill solid waste (OMSW) and concentrated olive mill wastewater (COMWW) was examined at different heating rates ranging from 5 to $50 \mathrm{~K} / \mathrm{min}$ in inert atmosphere using the technique of thermo gravimetric analysis. Avrami theory and iso-conversional Starink approach were used in this work to evaluate the kinetic parameters, including apparent activation energy $\left(E_{a}\right)$ and reaction order $(n)$. For the range of conversion degree investigated $(20-80 \%)$, the values of apparent activation energy for olive mill solid waste (OMSW) were 147.51-158.79 KJ/mol and 200.13-212.51 KJ/mol for hemicellulose and cellulose respectively. Whilst the apparent activation energy of concentrated olive mill wastewater (COMWW) varied from 128.41 to $138.85 \mathrm{KJ} / \mathrm{mol}$ and from 201.3 to $226.67 \mathrm{KJ} / \mathrm{mol}$ for hemicellulose and cellulose respectively. With varied temperature $(515-753 \mathrm{~K})$, the corresponding values of reaction order was increased from 0.1004 and 0.1061 to 0.1787 and 0.2886 , along with a decrease to 0.1220 and 0.1889 for OMSW and COMWW respectively.
\end{abstract}

Keywords: Olive mill solid waste; Olive mill wastewater; Pyrolysis; TGA; Thermochemical treatment

\section{Introduction}

In the view of shortage of fossil fuels and with the increasing concerns regarding human impacts on the environmental, renewable energy sources and waste materials play an important role as a viable alternative to fossil fuels for both production of chemicals and energy generation [1]. Biomass in general and agricultural waste in particular seems to be a realistic alternative power generation leading to environmental, economical and technical benefits $[2,3]$.

In Mediterranean basin countries, olive oil production is one of the most important agricultural industries. The olive oil industry shows great relevance from an environmental sustainability viewpoint due to quantity and difficulty of treatment of related waste. The olive oil production, in fact, is characterized by relevant amounts of by products, namely solid wastes, named olive mill solid waste (OMSW), and liquid wastes, usually named olive mill wastewater [4]. Olive wastes seem to be a promising energy source to mitigate greenhouse gas emissions. Their thermal valorization eliminates them; increases the exploitations output and decrease their production costs.

Treatment and disposal of olive mill wastes are presently one of the most serious environmental problems in these Mediterranean countries. The most common methods for managing olive mill waste disposal are landfilling, incineration and farmland applications, but none of these methods are exempt from drawbacks. Olive mill wastewater can be applied to agricultural, forest or disturbed lands as fertilizer [5-9]. However, the presence of metals and trace elements in wastewater limits their use in agricultural application as a fertilizer. Disposal of olive mill wastes through landfilling should be avoided as it subtracts the soil from agricultural use. On the other hand, incineration reduces the volume of the olive mill wastes, but it is costly and generates emissions to air, soil and water [10].

Recently, new alternative disposal methods such as pyrolysis, combustion, gasification and liquefaction are currently being investigated which minimize the currently drawbacks. Thermochemical conversion process presents several environmental advantages such as the reduction in mass and volume of disposed solids, the reduction in pollutants and the potential for energy recovery [11-13]. Thermochemical conversion process such as pyrolysis could be an alternative and viable option for environmentally acceptable way to manage olive mill wastes disposal. Thermo gravimetric analysis (TGA) is one of the most commonly used techniques to study the primary reactions of decomposition of solids. In the case of carbonaceous materials (lignocelluloses, municipal solid wastes, plastic etc.), thermo gravimetric techniques have been used for the identification of the different fractions of polymers present in the material, and their proportions, to determine the decomposition kinetic constants or as a previous step in refuse incineration and pyrolysis. TG is normally performed in either an isothermal or non-isothermal mode. Evaluating the reaction kinetics by a non-isothermal TG is advantageous in that considerably fewer experimental data are required than in the isothermal method, and the kinetics can be probed over the entire temperature range in a continuous manner [14-20].

Many mathematical approaches have been developed to calculate the kinetic parameters, in terms of Coats-Redfern, Freeman and Carroll method [21,22]. These methods are usually based on the

*Corresponding author: Guida MY, Organic Chemistry and Analytical Laboratory, Faculty of Science and Technology of Beni Mellal, University Sultan Moulay Slimane, BP 523, 23000 Beni Mellal, Morocco, Tel: +523480218; Fax: +523481351; E-mail:y.guida@usms.ma

Received June 23, 2016; Accepted June 27, 2016; Published October 28, 2017

Citation: Guida MY, Bouaik H, El Mouden L, Moubarik A, Aboulkas A, et al. (2017) Utilization of Starink Approach and Avrami Theory to Evaluate the Kinetic Parameters of the Pyrolysis of Olive Mill Solid Waste and Olive Mill Wastewater. J Adv Chem Eng 7: 155. doi: 10.4172/2090-4568.1000155

Copyright: (c) 2017 Guida MY, et al. This is an open-access article distributed under the terms of the Creative Commons Attribution License, which permits unrestricted use, distribution, and reproduction in any medium, provided the original author and source are credited. 
Citation: Guida MY, Bouaik H, El Mouden L, Moubarik A, Aboulkas A, et al. (2017) Utilization of Starink Approach and Avrami Theory to Evaluate the Kinetic Parameters of the Pyrolysis of Olive Mill Solid Waste and Olive Mill Wastewater. J Adv Chem Eng 7: 155. doi: 10.4172/20904568.1000155

Page 2 of 8

preliminary assumption of a certain reaction order and reaction model, such as nucleation, mampel, diffusional, autocatalytic and contracting geometry. Then the apparent activation energy and preexponential factor are calculated simultaneous, but not separately. Consequently, these approaches are viewed as the model-fitting method [23]. This kind of method often employs the single and simple reaction model during the reaction process, which can result in a substantial divergence. This divergence results from the difference between the ideal reaction model and actual heterogeneous reaction process consisting of series of parallel and sequential reactions. Besides, the values of activation energy and factor exponential A will vary greatly on condition that different reaction model is preliminary assumed; but the two parameters can always get good linear regression between each other. This manifestation of kinetic compensation effect could result in some difficult in determining the accurate reaction model, since more than one reaction model can be obtained using this method. Therefore, adopting the model-fitting method may bring about the highly uncertain values of the kinetic parameters [24-39].

In terms of the studies of pyrolysis kinetics of olive mill solid waste (OMSW) and concentrated olive mill wastewater (COMWW), most investigations adopt the model-fitting method, and usually take the first-order reactions as the presumed reaction model. Some other researches generally assume a certain reaction order and a particular reaction model. The main objective of this study is to investigate the variation of pyrolysis kinetics of olive mill solid waste and concentrated olive mill wastewater at different conversion fractions and reaction temperature. In our work, we were able to make a kinetic study of olive mill wastes such as olive mill solid waste and olive mill wastewater. We obtained reliable and consistent results. These results allowed us to understand well the process of pyrolysis of olive mill solid waste and olive mill wastewater.

\section{Experimental}

\section{Materials and sample preparation}

The olive mill wastes samples used in this research work was sampled from the olive oil process (Mâasra in Morocco), located in Béni-Mellal area (Central Zone) which located about $303 \mathrm{Km}$ of Rabat. The olive mill wastewater samples were concentrated via evaporation with a rotating evaporator at atmospheric pressure to a concentrated remainder that could then be dried to a residue. On the other hand, the solid waste samples were air-dried, and both samples were ground to obtain a uniform material of an average particle size (0.1-0.2 $\mathrm{mm}$ ). Table 1 shows the chemical compositions of samples while the physicalchemical characterization of the raw OMWW depicted in Table 2.

\begin{tabular}{|l|c|c|}
\hline & OMSW/\% & COMWW/\% \\
\hline Proximate analysis & & \\
\hline Moisture & 8.3 & 3.8 \\
\hline Volatile matter & 73.5 & 61.4 \\
\hline Ash & 4.5 & 25.1 \\
\hline Fixed carbon & 13.7 & 9.7 \\
\hline Elemental analysis & & \\
\hline C & 45.5 & 39.7 \\
\hline H & 5.3 & 4.6 \\
\hline N & 1.8 & 1.7 \\
\hline O & 47.4 & 46 \\
\hline Chemical analysis & & 17.4 \\
\hline Hemicellulose & 21.6 & 23.3 \\
\hline Cellulose & 30.4 & 34.2 \\
\hline Lignin & 43.5 & \\
\hline
\end{tabular}

Table 1: Main characteristic of OMSW and COMWW.

\begin{tabular}{|l|c|}
\hline Parameters & Values \\
\hline $\mathrm{pH}\left(25^{\circ} \mathrm{C}\right)$ & 5.15 \\
\hline Electrical conductivity $\mathrm{Ms} / \mathrm{cm}$ à $20^{\circ} \mathrm{C}$ & 6.73 \\
\hline Total phenols g/L & 13.35 \\
\hline Total $\mathrm{COD} \mathrm{gO}_{2} / \mathrm{I}$ & 70.40 \\
\hline
\end{tabular}

Table 2: Physical-chemical determination of the raw OMWW.

\section{Experimental techniques}

Olive mill solid waste and COMWW (Concentrated olive mill wastewater) samples were subjected to thermo gravimetric analyses in an inert atmosphere of nitrogen. Rheometrix Scientific STA 1500 TGA analyzer was used to measure and records the sample mass change with temperature over the course of the pyrolysis reaction. Thermo gravimetric curves were obtained at four different heating rates $\left(5,10,20\right.$ and $\left.50 \mathrm{~K} \cdot \mathrm{min}^{-1}\right)$ between 300 and $1173 \mathrm{~K}$. Nitrogen gas was used as an inert purge gas to displace air in the pyrolysis zone, thus avoiding unwanted oxidation of the sample. A flow rate of around $60 \mathrm{ml} . \mathrm{min}^{-1}$ was fed to the system from a point below the sample and a purge time of $60 \mathrm{~min}$ (to be sure the air was eliminated from the system and the atmosphere is inert). The balance can hold a maximum of $45 \mathrm{mg}$; therefore, all samples amounts used in this study averaged approximately $20 \mathrm{mg}$. the reproducibility of the experiments is acceptable, and the experimental data presented in this paper corresponding to the different operating conditions are the mean values of runs carried out two or three times.

\section{Kinetic modeling}

Kinetic analysis techniques have been classified as either model fitting (i.e., the identification of a kinetic reaction model) or isoconversional (i.e., model-free). The latter is preferred by researchers for two reasons [40-42]: (1) model-free kinetics are sufficiently flexible to allow for a change in Mechanism during a reaction, and (2) mass transfer limitations are reduced by the use of multiple heating rates. In contrast, model fitting kinetic methods generally involve a single heating rate, which is disadvantageous because the activation energy varies with the heating rate due to mass/energy transfer effects.

General kinetic equation of heterogeneous solid-state thermal transformation at a linear temperature heating rate has been traditionally described as,

$$
\begin{aligned}
& \frac{d \alpha}{d t}=K(T) \cdot f(\alpha) \\
& \beta \frac{d \alpha}{d T}=A \cdot e^{-E / R T} \cdot f(\alpha)
\end{aligned}
$$

The conversion of biomass can be calculated as:

$$
K(T)=A \cdot \exp \left(\frac{-E}{R T}\right)
$$

The rate of heterogeneous solid-state reactions can be generally described by:

$$
\alpha=\frac{m_{0}-m_{t}}{m_{0}-m_{\infty}}
$$

Where $m_{t}$ is the mass of the sample at a given time $t$ and $m_{0}$ and $m_{\infty}$ refer to values at the beginning and the end of the mass loss event of interest.

$k(T)$ is a temperature-dependent constant and $f(\alpha)$ is the reaction model, which describes the dependence of the reaction rate on the extent of reaction. The mathematical description of the data for a single step solid-state decomposition is usually defined in terms of a kinetic 
Citation: Guida MY, Bouaik H, El Mouden L, Moubarik A, Aboulkas A, et al. (2017) Utilization of Starink Approach and Avrami Theory to Evaluate the Kinetic Parameters of the Pyrolysis of Olive Mill Solid Waste and Olive Mill Wastewater. J Adv Chem Eng 7: 155. doi: 10.4172/20904568.1000155

Page 3 of 8

triplet: the activation energy, $E$; the Arrhenius parameter, $A$; and an algebraic expression of the kinetic model as a function of the fractional conversion $\alpha, f(\alpha)$. These terms can be related to experimental data as follows:

$$
\frac{d \alpha}{d t}=\left(\frac{A}{\beta}\right) \cdot \exp \left(\frac{-E}{R T}\right) \cdot f(\alpha)
$$

Where $\beta$ is the linear heating rate $(\beta=d T / d t)$ and it is a constant.

Starink method: According to the Starink method, the approximate expression of FWO method and KAS method can be transformed into the same general formula $[43,44]$ as:

$$
\ln \left(\frac{\beta}{T^{S}}\right)=C_{S}-\left(\frac{B E}{R T}\right)
$$

Where for the FWO method; $s=0, B=0.4567$; for the KAS method; $s=2, B=1$. After a further exact analysis by Starink, the parameters of $\mathrm{s}$ and $\mathrm{B}$ has been adjusted to $s=1.8, B=1.0033$, respectively. Besides, it has been verified by Starink that the precision of apparent activation energy calculated by this method is higher than those of FWO method and KAS method. Hence the Starink method can be described as:

$$
\ln \left(\frac{\beta}{T^{1.8}}\right)=C_{S}-1.0037\left(\frac{E}{R T}\right)
$$

For a given conversion fraction $\alpha$, the points of $\ln \left(\beta / T^{1.8}\right)$ versus $1 / T$ at different temperature heating rates can be fitted to a straight line, and the slope of the line corresponds to $-1.0037 E / R$. Hence the apparent activation energy $E$ can be calculated from the slope of the straight line.

Avrami theory: Reaction order is also a significant parameter to investigate the pyrolysis characteristic of biomass, besides apparent activation energy. In order to calculate the reaction order, Avrami theory was used in this study, and it can be described $[44,45]$ as:

$$
\alpha=1-\exp \left(\frac{-k(T)}{\beta^{n}}\right)
$$

Where $\alpha, \beta$ and $k(T)$ are the same parameters described in Equation 3 , and as the exponent of $\beta, \mathrm{n}$ represents the reaction order. Taking the double logarithm and transposing, Equation 7 is transformed into the following equation:

$$
\ln (-\ln (1-\alpha))=\ln A-\frac{E}{R T}-n \ln \beta
$$

For a given temperature, $T$, the points of $\ln (-\ln (1-\alpha))$ versus $\ln \beta$ at different temperature heating rates can be fitted to a straight line, and the slope of the line corresponds to $-n$. Thus, the reaction order can be deduced from the slope of the straight line.

\section{Results and Discussion}

\section{Thermal decomposition characteristics of OMSW and COMWW}

Pyrolysis profiles under inert atmosphere (mass loss TG and derivative mass loss DTG) of OMSW and COMWW are reported in Figures 1 and 2. It is seen that TG and DTG profiles of OMSW and COMWW are similar to those described in the literature [46-50]. In general, thermal decomposition of OMSW and COMWW was achieved in three different temperature regimes: drying, main devolatilization and continuous slight devolatilization. Up to about 393K, moisture in the sample was evaporated, resulting in mass loss. The mass loss in this first stage is approximately $8 \%$ for OMSW and $3.4 \%$ for COMWW. After drying, pyrolytic thermal decomposition reaction took place in the temperature range of about $423-707 \mathrm{~K}$ producing condensable

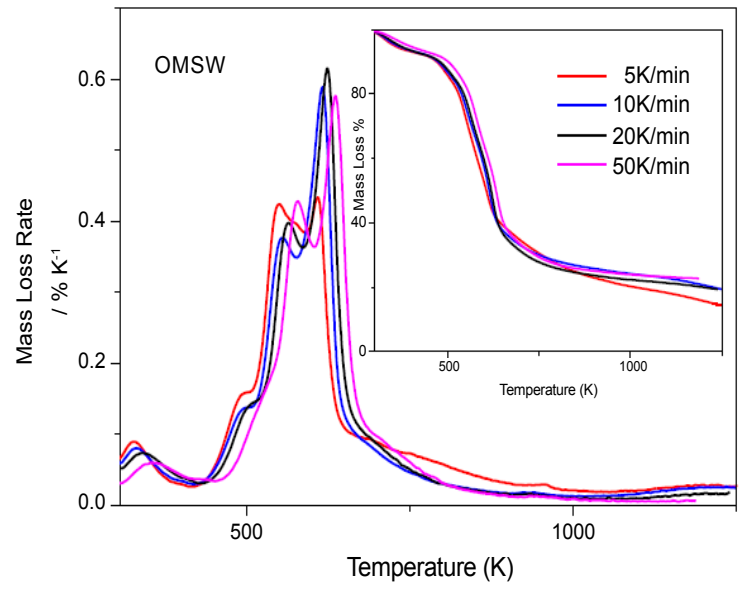

Figure 1: TG and DTG curves for the pyrolysis of OMSW at heating rates of $5,10,20$ and $50 \mathrm{~K} / \mathrm{min}$.

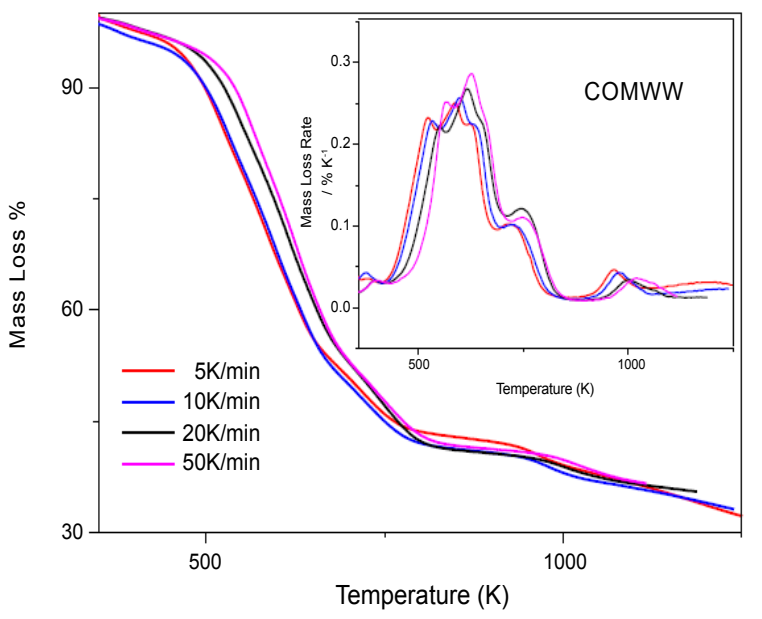

Figure 2: TG and DTG curves for the pyrolysis of COMWW at heating rates of $5,10,20$ and $50 \mathrm{~K} / \mathrm{min}$.

and non-condensable volatile gases. The main devolatilization of the COMWW and OMSW starts at 423 and $436 \mathrm{~K}$, respectively. Therefore, the COMWW organic content allows the thermal decomposition of cellulosic compounds at lower temperatures. This result can be explained by the characteristics of the organic compounds present in OMWW. The devolatilization step finishes earlier $(707 \mathrm{~K})$ for COMWW compared to OMSW (678 K). This behavior may be related to the original composition of OMSW being richer in cellulose. The mass loss of the main pyrolysis is $57.8 \%$ and $46.2 \%$ for OMSW and COMWW, respectively. This phenomenon is in full accordance with the lowest percentage of ash in OMSW approximate analysis.

On the DTG curves, the temperatures at which maximum rate of mass loss occurred are described by the position of the peaks in the curve. The difference in TG and DTG indicates that the two samples differ in reactivity. The OMSW and COMWW samples revealed large differences in their decomposition behavior. This step is associated with thermal volatilization of the compounds related to hemicellulose and cellulose present in two materials. In the case of the lignocelluloses material, the temperature of degradation and the thermal degradation rate of the hemicelluloses and lignin are lower than the values that 
Citation: Guida MY, Bouaik H, El Mouden L, Moubarik A, Aboulkas A, et al. (2017) Utilization of Starink Approach and Avrami Theory to Evaluate the Kinetic Parameters of the Pyrolysis of Olive Mill Solid Waste and Olive Mill Wastewater. J Adv Chem Eng 7: 155. doi: 10.4172/20904568.1000155

Page 4 of 8

can be found on the cellulose [51]. Therefore, the initial temperature of degradation is higher in OMSW, which present a high amount of cellulose in comparison with COMWW as the literature reports [52]. However, the difference in the fraction of cellulose and hemicelluloses between two materials is relatively greater, which indicates that the different properties of the pyrolysis process between COMWW and OMSW are mainly affected by the percentage of cellulose and hemicelluloses [53]. In addition, it should be pointed out that a fuel with a higher percentage of ashes and impurities in this composition presents a lower initial temperature of degradation, and this effect takes place in the case of COMWW, due to a higher amount of ashes [54]. After the main pyrolytic process, there is slow and continuous degradation between 673 and $873 \mathrm{~K}$ attributed to lignin degradation. In the case of COMWW, a slight mass loss between 873 and $1073 \mathrm{~K}$ can be assigned to the decomposition of inorganic material [55]. The decomposition rate of COMWW is lower than OMSW (DTG ${ }_{\max }$ value). The values obtained for this parameter confirms the lower reactivity of COMWW in comparison with OMSW. Residual masses at 1123 $\mathrm{K}$ are $21.5 \%$ of the initial mass for OMSW and $35.6 \%$ for COMWW. This behavior may be due to the presence of polyaromatic compounds which need higher temperature to be thermally destroyed [56,57]. Furthermore, with regard to the literature [58,59] and our study, COMWW has a high inorganic salt content which may explain the high amount of ash in the COMWW sample.

Heating rate is one of the most important parameters influencing the pyrolysis characteristics (Figures 1 and 2, Table 3). It was clear that the heating rate affects significantly the maximum decomposition rate, with maximum decomposition rate tending to increase and occur at higher temperatures when pyrolyzed at higher heating rates. The phenomenon related to this important change in the maximum pyrolysis rate can be interpreted by the fact that biomass has a heterogeneous structure and possesses a number of constituents. These constituents gave their characteristic individual decomposition peaks in definite temperature ranges in the pyrolysis process. When heating rate was sufficiently low during pyrolysis, most of these peaks can be seen as small broken lines or vibrations. However, at high heating rates, separate peaks did not arise because some of them were decomposed simultaneously, and several adjacent peaks were united to form overlapped broader and higher peaks $[54,55]$. This fact can be a consequence of heat and mass transfer limitations. With an increase in heating rate, the temperature in the furnace space can be a little higher as the temperature of a particle and the rate of decomposition are higher than the release of volatilities. Because of the heat transfer limitation, temperature gradients may exist in the particle. Temperature in the core of a particle can be a bit lower than temperature on its surface, and different decomposition processes or releasing rates can occur. This is the reason why it is necessary to have a small particle, homogenous sample and the heat transfer surface between the sample and the crucible as large as possible [56].

\section{Variation of apparent activation energy of OMSW and COMWW}

To evaluate the variation of the activation energy on the conversion fraction (conversion degree) during the major pyrolysis process. Thirteen levels of conversion a varying from $20 \%$ to $80 \%$ with an increment of $5 \%$ employed at different heating rates 5, 10, 20 and 50 $\mathrm{K} / \mathrm{min}$. The change of the conversion $\alpha$, depending on the temperature and at different heating rates is shown in Figures 3 and 4. Based on the model-free of Starink method, the regression lines of olive mill solid waste and concentrated olive mill wastewater are illustrated in Figures 5 and 6 . The calculated energy of activation and the square of correlation coefficient $\mathrm{R}^{2}$ are listed in Table 4 .

It can be seen from Table 4, that the apparent activation energy

\begin{tabular}{|c|c|c|c|c|c|c|c|c|c|}
\hline \multirow[t]{2}{*}{ Sample } & \multirow{2}{*}{$\begin{array}{l}\text { Heating rate/ } \\
\text { K.min }{ }^{-1}\end{array}$} & \multicolumn{4}{|c|}{ First step/K } & \multicolumn{4}{|c|}{ Second step/K } \\
\hline & & $T_{i}$ & $T_{\max }$ & $T_{f}$ & $\mathrm{DTG}_{\max }(\% / \mathrm{K})$ & $T_{i}$ & $T_{\max }$ & $T_{f}$ & $\mathrm{DTG}_{\max }(\% / \mathrm{K})$ \\
\hline \multirow{4}{*}{ OMSW } & 5 & 435 & 546 & 669 & 0.4242 & 669 & 606 & 654 & 0.4310 \\
\hline & 10 & 444 & 552 & 575 & 0.3780 & 575 & 611 & 667 & 0.5836 \\
\hline & 20 & 457 & 564 & 584 & 0.3930 & 584 & 623 & 686 & 0.6080 \\
\hline & 50 & 477 & 575 & 602 & 0.4293 & 602 & 636 & 677 & 0.5716 \\
\hline \multirow{4}{*}{ comww } & 5 & 423 & 512 & 535 & 0.2313 & 535 & 577 & 676 & 0.2479 \\
\hline & 10 & 434 & 530 & 547 & 0.2268 & 547 & 593 & 689 & 0.2555 \\
\hline & 20 & 440 & 534 & 550 & 0.2221 & 550 & 597 & 696 & 0.2646 \\
\hline & 50 & 448 & 546 & 567 & 0.2494 & 567 & 609 & 707 & 0.2843 \\
\hline
\end{tabular}

Table 3: Characteristics parameters of OMSW and COMWW during the pyrolysis process.

\begin{tabular}{|c|c|c|c|c|}
\hline Conversion degree & \multicolumn{3}{|c|}{ OMSW } & \multicolumn{2}{|c|}{ COMWW } \\
\hline $\boldsymbol{\alpha}$ & $\mathbf{E}_{\mathbf{a}} / \mathbf{K} / \mathbf{m o l}$ & $\mathbf{R}^{\mathbf{2}}$ (Correlation Coefficient) & $\mathbf{E}_{\mathbf{a}} / \mathbf{K} / \mathbf{m o l}$ & $\mathbf{R}^{\mathbf{2}}$ (Correlation Coefficient) \\
\hline 0.2 & 148.39 & 0.92342 & 128.74 & 0.95974 \\
\hline 0.25 & 154.68 & 0.97473 & 128.41 & 0.9646 \\
\hline 0.3 & 147.51 & 0.97493 & 129.73 & 0.97602 \\
\hline 0.35 & 150.34 & 0.97529 & 132.2 & 0.96487 \\
\hline 0.4 & 151.53 & 0.99931 & 136.74 & 0.9574 \\
\hline 0.45 & 158.79 & 0.99753 & 138.85 & 0.95213 \\
\hline 0.5 & 200.13 & 0.99747 & 201.3 & 0.95239 \\
\hline 0.55 & 209.49 & 0.99319 & 212.64 & 0.93197 \\
\hline 0.6 & 208.04 & 0.99324 & 211.75 & 0.96115 \\
\hline 0.65 & 209.79 & 0.99392 & 221.82 & 0.95034 \\
\hline 0.7 & 211.67 & 0.95592 & 226.07 & 0.9596 \\
\hline 0.75 & 211.8 & 0.9569 & 210.62 & 0.9594 \\
\hline 0.8 & 212.51 & 0.9557 & 176.08 & 0.9603 \\
\hline Mean & 182.66 & --- & -- & Cellulose \\
\hline
\end{tabular}

Table 4: Activation energy $\left(E_{a}\right)$ and correlation coefficient $\left(R^{2}\right)$ deduced from the Starink method for OMSW and COMWW. 
Citation: Guida MY, Bouaik H, El Mouden L, Moubarik A, Aboulkas A, et al. (2017) Utilization of Starink Approach and Avrami Theory to Evaluate the Kinetic Parameters of the Pyrolysis of Olive Mill Solid Waste and Olive Mill Wastewater. J Adv Chem Eng 7: 155. doi: 10.4172/20904568.1000155

Page 5 of 8

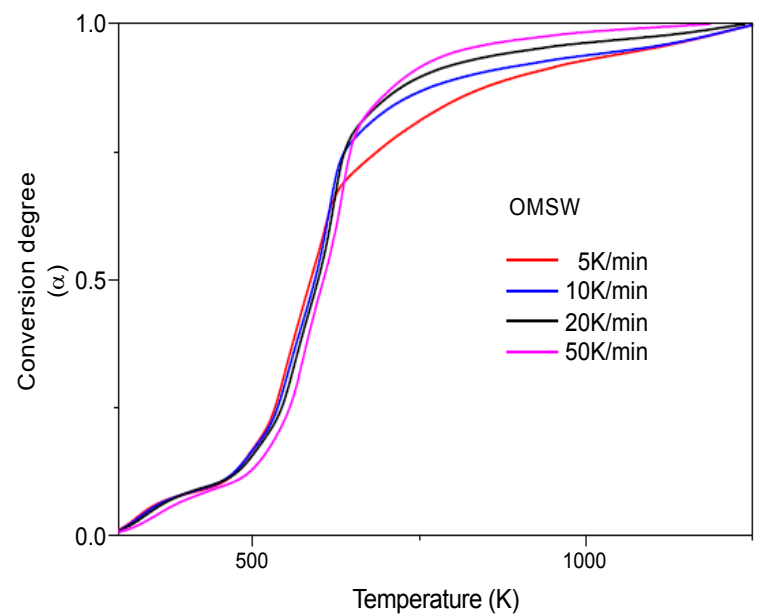

Figure 3: Variation of conversion as a function of temperature at different heating rates of OMSW.

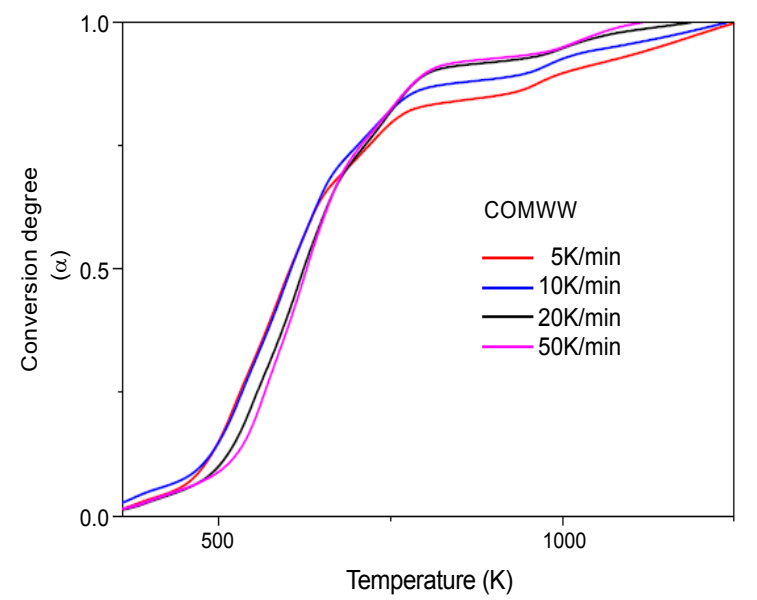

Figure 4: Variation of conversion as a function of temperature at different heating rates of COMWW.

of the two both samples (OMSW and COMWW) varied greatly with different conversion fractions, instead of keeping constant. From Figure 7 , one can notice the same shapes of the curves $E_{a}$ versus $\alpha$. This result indicates that the existence of on-step that occurs in hemicelluloses and cellulose decomposition of two materials. The apparent activation energies have a value of 147.51-158.79 KJ/mol and 128.41-138.85 KJ/ mol for the hemicelluloses degradation of OMSW and COMWW, respectively. The apparent value of activation energy is about 200.13$212.51 \mathrm{KJ} / \mathrm{mol}$ and $201.3-226.67 \mathrm{KJ} / \mathrm{mol}$ for the cellulose degradation of OMSW and COMWW, respectively. Activation energy is an obstacle that must be overcome before a chemical reaction is generated and higher value of activation energy means more difficult of a reaction occurs. It determines the reactivity and sensitivity of a reaction rate. So, different activation energies at different fractional conversions illustrate the multistage characteristic of the thermal decomposition process of OMSW and COMWW. It also shows the complexity of this physical and chemical transformation, and it should contain different reactions at different reaction stages.

Several researches [57-60] carried out non-isothermal kinetic analysis of the pyrolysis of olive mill solid waste in the heating rate

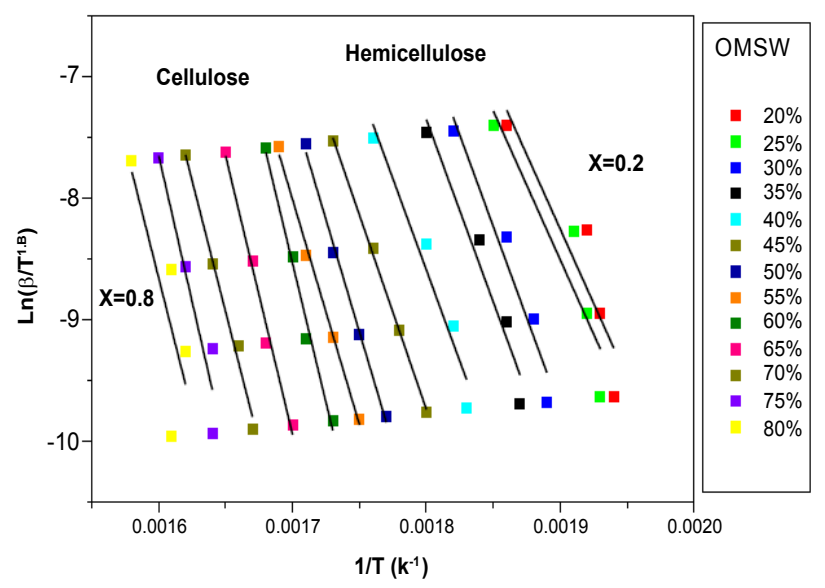

Figure 5: Regression lines to apparent activation energy proposed by Starink method for OMSW at heating rates of $5,10,20$ and $50 \mathrm{~K} / \mathrm{min}$.

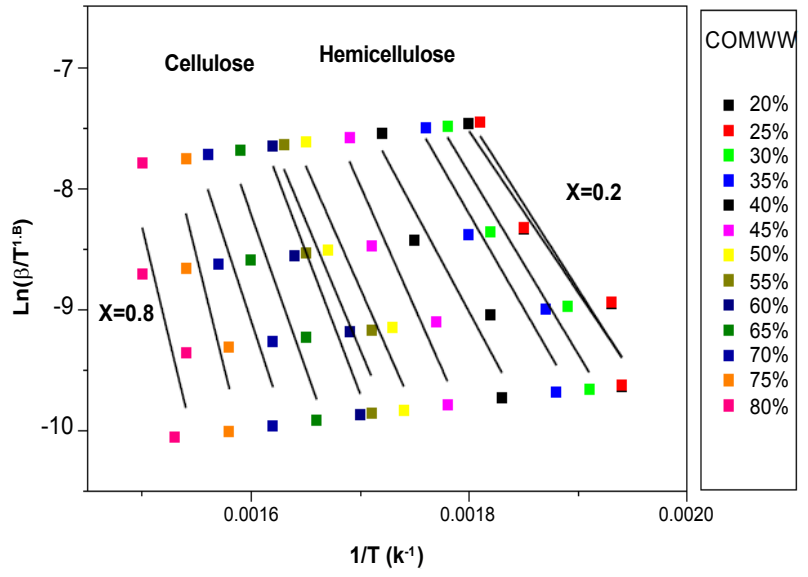

Figure 6: Regression lines to apparent activation energy proposed by Starink method for COMWW at heating rates of 5, 10, 20 and $50 \mathrm{~K} / \mathrm{min}$.

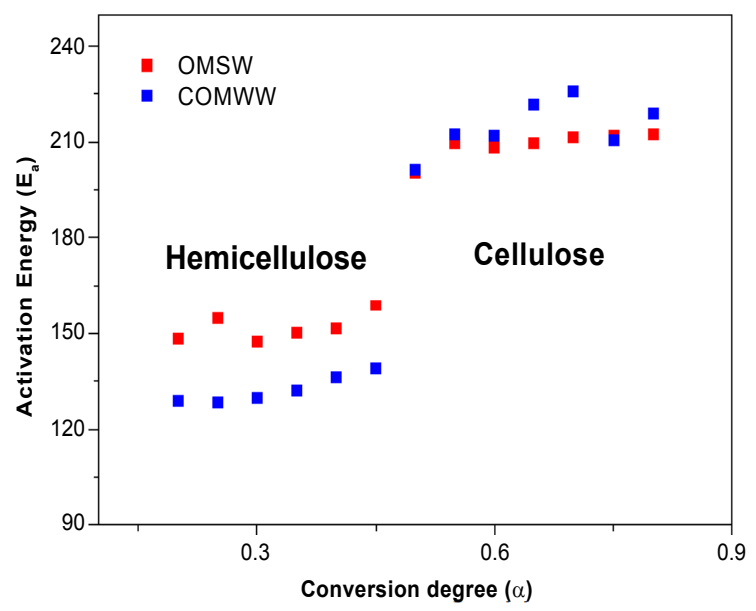

Figure 7: Dependence of activation energy on the conversion ( $\alpha$ ) for decomposition of hemicellulose and cellulose of OMSW and COMWW according to Starink method.

range of $2-50 \mathrm{~K} / \mathrm{min}$. It was reported that the apparent activation energy in the $0.1-0.8$ conversion interval ranged from $162-215 \mathrm{KJ} / \mathrm{mol}$. 
Citation: Guida MY, Bouaik H, El Mouden L, Moubarik A, Aboulkas A, et al. (2017) Utilization of Starink Approach and Avrami Theory to Evaluate the Kinetic Parameters of the Pyrolysis of Olive Mill Solid Waste and Olive Mill Wastewater. J Adv Chem Eng 7: 155. doi: 10.4172/20904568.1000155

Thus, the result in this study showed the similar range to those obtained in the present study in spite of the small property differences between olive mill solid waste and concentrated olive mill wastewater. Other researchers analysed the thermal degradation of sugarcane bagasse, activation energy values found were $105 \mathrm{KJ} / \mathrm{mol}$ and $235 \mathrm{KJ} / \mathrm{mol}$ for hemicellulose and cellulose respectively. Other researchers investigated the kinetics of pyrolysis of rice husk under non-isothermal conditions in nitrogen. The experiments were conducted at different temperature heating rates from 5 to $100 \mathrm{~K} / \mathrm{min}$, and the energies of activation calculated was found to range from 72.7 to $97.1 \mathrm{~kJ} / \mathrm{mol}$. Researchers have also paid special attention to investigate the three biochemical composition of biomass, including cellulose, hemicellulose and lignin. As suggested by several authors [61], the apparent activation energy of cellulose, hemicellulose and lignin is generally about two hundreds, one hundreds and tens $\mathrm{kJ} / \mathrm{mol}$, respectively. Thus, it indicates that property of the biomass is also a key factor determining the variation of apparent activation energy in the pyrolysis process.

\section{Variation of reaction order of OMSW and COMWW}

During the major pyrolysis process, in order to evaluate the dependence of reaction order on temperature, seven levels of temperature were also employed at four temperature heating rates of 5 , 10,20 and $50 \mathrm{~K} / \mathrm{min}$. Adopting the Avrami theory, the regression lines of olive mill solid waste and concentrated olive mill wastewater are shown in Figures 8 and 9. And the calculated reaction order is listed in Tables 5 and 6 . The corresponding values of $R^{2}$ are presented in Tables 5 and 6. It can be seen from Tables that the Avrami theory is suitable for determining the kinetic parameter of reaction order, based on the data of $R^{2}$ calculated. The reaction order of olive mill solid waste and concentrated olive mill wastewater both differed greatly rather than remained constant. However, they showed the same variation trend. With varied temperatures (515-753 K), the reaction order of olive mill solid waste was first increased from 0.1004 to 0.1787 and then decreased to 0.1220 . As for the concentrated olive mill wastewater, it increased from 0.1061 to 0.2886 and decreased to 0.1889 afterwards.

Consequently, it can be observed that the varying currents of apparent activation energy and the reaction order for olive mill solid waste and concentrated olive mill wastewater are different. From the view of the varied mathematical mutual relation of the

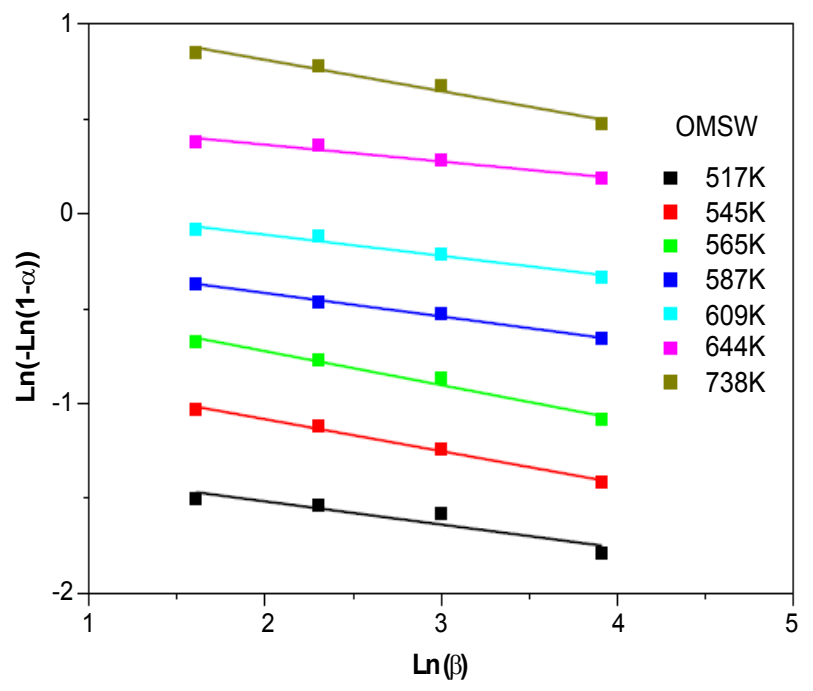

Figure 8: Regression lines to reaction order proposed by Avrami theory for OMSW at heating rates of $5,10,20$ and $50 \mathrm{~K} / \mathrm{min}$.

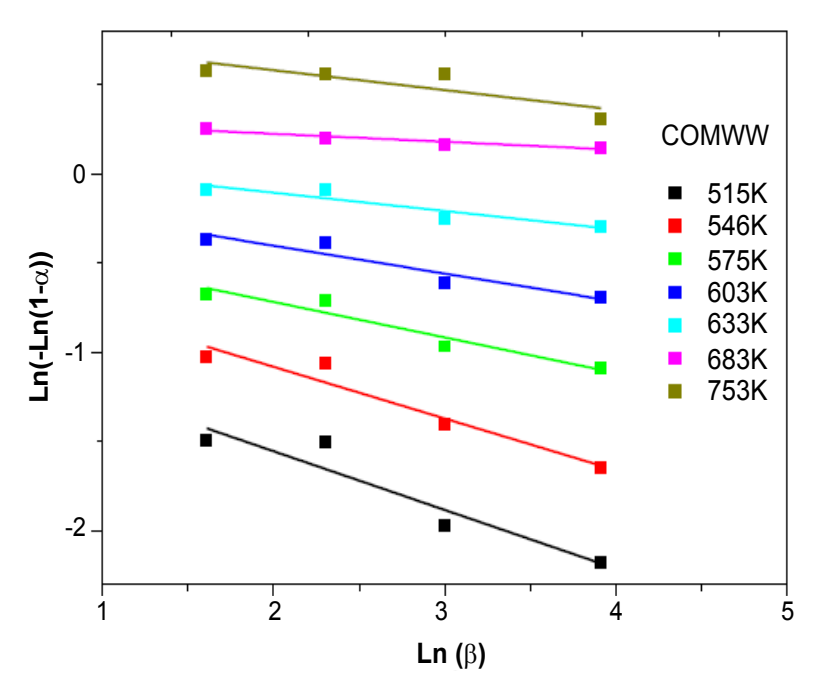

Figure 9: Regression lines to reaction order proposed by Avrami theory for OMSW at heating rates of $5,10,20$ and $50 \mathrm{~K} / \mathrm{min}$.

\begin{tabular}{|l|c|c|c|c|}
\hline Sample & Temperature (K) & Slope & $\mathbf{n}$ & $\mathbf{R}^{\mathbf{2}}$ \\
\hline \multirow{4}{*}{ OMSW } & 517 & -0.1004 & 0.1004 & 0.951 \\
\cline { 2 - 5 } & 545 & -0.1117 & 0.1117 & 0.922 \\
\cline { 2 - 5 } & 565 & -0.1239 & 0.1239 & 0.996 \\
\cline { 2 - 5 } & 587 & -0.1647 & 0.1647 & 0.991 \\
\cline { 2 - 5 } & 609 & -0.1684 & 0.1684 & 0.983 \\
\cline { 2 - 5 } & 644 & -0.1787 & 0.1787 & 0.963 \\
\hline
\end{tabular}

Table 5: Slope, reaction order $(n)$ and correlation coefficient $\left(R^{2}\right)$ deduced from Avrami theory for OMSW.

\begin{tabular}{|l|c|c|c|c|}
\hline Sample & Temperature (K) & Slope & $\mathbf{n}$ & $\mathbf{R}^{\mathbf{2}}$ \\
\hline \multirow{4}{*}{ comWW } & 515 & -0.1061 & 0.1061 & 0.977 \\
\cline { 2 - 5 } & 546 & -0.1505 & 0.1505 & 0.989 \\
\cline { 2 - 5 } & 575 & -0.1988 & 0.1988 & 0.984 \\
\cline { 2 - 5 } & 603 & -0.2289 & 0.2289 & 0.916 \\
\cline { 2 - 5 } & 633 & -0.2886 & 0.2886 & 0.943 \\
\cline { 2 - 5 } & 683 & -0.1597 & 0.1597 & 0.911 \\
\cline { 2 - 5 } & 753 & -0.1889 & 0.1889 & 0.997 \\
\hline
\end{tabular}

Table 6: Slope, reaction order $(n)$ and correlation coefficient $\left(R^{2}\right)$ deduced from Avrami theory for COMWW.

two kinetic parameter for the two samples, it can be further affirmed that the pyrolysis reaction mechanisms of olive mill solid waste and concentrated olive mill wastewater are obviously different.

Assuming the addition of three independent parallel reactions, corresponding to three-pseudo components linked to the hemicellulose, cellulose and lignin, several authors in their works [62] simulated the corn straw pyrolysis using two different three-pseudo component models. It was observed that the three-pseudo component model with order kinetics was more accurate than the model with first-order kinetics at most cases. The application of first-order reaction models in biomass pyrolysis kinetics has become almost formulaic, and their indiscriminate acceptance has occurred without rigorous verification or sufficient awareness of their fundamental limitations. Therefore, it further demonstrates that pyrolysis of biomass is a complicated physiochemical process, and it might hard to determine a single value of reaction order during the whole process. In addition, various mathematical approaches can be adopted in combination, in order 
Citation: Guida MY, Bouaik H, El Mouden L, Moubarik A, Aboulkas A, et al. (2017) Utilization of Starink Approach and Avrami Theory to Evaluate the Kinetic Parameters of the Pyrolysis of Olive Mill Solid Waste and Olive Mill Wastewater. J Adv Chem Eng 7: 155. doi: 10.4172/20904568.1000155

to improve the calculation accuracy of kinetic parameters of biomass pyrolysis. Some studies have also been conducted to investigate the reaction order of the three biochemical composition of biomass [6367]. Theses researches reported that the pyrolysis of cellulose can be described by the first order of reaction, whilst the three-order reaction may be the most suitable assumption for the lignin component, according to the results other authors investigated the pyrolysis of hemicellulose employing the assumption of second reaction order, and observed that the hemicellulose of different biomass materials differed greatly in reaction order. Therefore, the difference of reaction order between olive mill solid waste and concentrated olive mill wastewater is also concerned with those three biochemical compositions with the different reaction order. In addition, the ash content in the biomass is another crucial factor, which may alter the reaction path, since the alkali metals in the ash can catalyze the formation of the char during the pyrolysis process, which has a direct correlation with the chemical reactivity of biomass pyrolysis.

\section{Conclusion}

TGA of OMSW and COMWW indicates that the two samples both showed two relatively large weight losses. The characteristic parameters of $T_{i}, T_{\max }, T_{f}$ and $D T G_{\text {max }}$ were found to have inconsistent variation trends. With conversion fraction increasing from $20 \%$ to $80 \%$, the results showed that apparent activation energy obtained for the decomposition of hemicelluloses and cellulose derived from OMSW was given as $147.51-158.79 \mathrm{KJ} / \mathrm{mol}$ and $200.13-212.51 \mathrm{KJ} / \mathrm{mol}$, while for COMWW; the values were 128.41 to $138.85 \mathrm{KJ} / \mathrm{mol}$ and 201.3 to $226.67 \mathrm{KJ} / \mathrm{mol}$, respectively. For the range of temperatures investigated $(515-753 \mathrm{~K})$, the reaction order of OMSW ranged from 0.1004 to 0.1787 , and 0.1061 to 0.2886 for COMWW.

\section{References}

1. McKendry $P$ (2002) Energy production from biomass (part 1): overview of biomass. Bioresource Technol 83: 37-46.

2. Yang HP, Yan R, Chen HP, Lee DH, Zheng CG (2007) Characteristics of hemicellulose, cellulose and lignin pyrolysis. Fuel 86: 1781-1788.

3. Seo DK, Park SS, Hwang J, Yu TU (2010) Study of the pyrolysis of biomass using thermo-gravimetric analysis (TGA) and concentration measurements of the evolved species. J Anal Appl Pyrol 89: 66-73.

4. Bridgwater AV (2012) Review of fast pyrolysis of biomass and product upgrading. Biomass Bioenergy; 38: 68-94.

5. Manya JJ, Velo E, Puigjaner L (2003) Kinetics of biomass pyrolysis: a reformulated three-parallel-reactions model. Ind Eng Chem Res 42: 434-441.

6. Varhegyi G, Antal MJ, Jakab E, Szabo P (1997) Kinetic modeling of biomass pyrolysis. J Anal Appl Pyrol 42: 73-87.

7. Raveendran K, Ganesh A, Khilar KC (1995) Influence of mineral matter on biomass pyrolysis characteristics. Fuel 74: 1812-1822.

8. Sanchez SL, Lopez-Gonzalez D, Villasenor J, Sanchez P, Valverde JL (2012) Thermogravimetric-mass spectrometric analysis of lignocellulosic and marine biomass pyrolysis. Bioresource Technol 109: 163-172.

9. Ninan KN (1989) Kinetics of solid-state thermal-decomposition reactions. J Therm Anal 35: 1267-1278.

10. Teng HS, Lin HC, Ho JA (1997) Thermogravimetric analysis on global mass loss kinetics of rice hull pyrolysis. Ind Eng Chem Res 36: 3974-3977.

11. Brachi P, Chirone R, Miccio F, Miccio M, Picarelli A, et al. (2014) Fluidized bed cogasification of biomass and polymeric wastes for a flexible end-use of the syngas: focus on bio-methanol. Fuel 128: 88-98.

12. Verhoeff F, Adell A, Boersma AR, Pels JR, Lensselink J, et al. (2011) Torrefaction Technology for the Production of Solid Bioenergy Carriers From Biomass and Waste. Report ECN-E-11-039, ECN, Petten.

13. Caputo AC, Scacchia F, Pelagasse PM (2003) Disposal of by-product in olive oil industry: waste to energy solutions. Applied Thermal Engineering 23: 197-214.
14. Miccio F, Ruoppolo G, Russo S, Urciuolo M, De Riccardis A (2014) Fluidized bed combustion ofwet biomass fuel (olive husks). Chemical Engineering Transactions 37: 1-6.

15. Syu FS, Chiueh PT (2012) Process simulation of rice straw torrefaction Sustainable Environment Research 22: 177-183.

16. Håkansson K, Nordin A, Nordwaeger M, Olofsson I, Svanberg M (2010) Process and System Integration Aspects of Biomass Torrefaction, the Proceeding of the $18^{\text {th }}$ European Biomass Conference and Exhibition EU BC \& E Lyon. France, 2010

17. Sarvaramini A, Assima GP, Beaudoin G, Larachi F (2014) Biomass torrefaction and $\mathrm{CO} 2$ capture using mining wastes a new approach for reducing greenhouse gas emissions of co-firing plants. Fuel 115: 749-757.

18. Vyazovkin S, Wight CA (1998) Isothermal and non-isothermal kinetics of thermally stimulated reactions of solids. International Reviews in Physical Chemistry $17:$ 407-433.

19. Prins MJ, Ptasinski KJ, Jassen FJJG (2006) Torrefaction of wood. Part 1. Weight loss kinetics. Journal of Analytical and Applied Pyrolysis 77: 28-34.

20. Branca C, Di Blasi C (2003) Kinetics of the isothermal degradation of wood in the temperature range 528-708 K. Journal of Analytical and Applied Pyrolysis 67: $207-219$

21. Heal GR (1999) Evaluation of the integral of the Arrhenius function by a series of Chebyshev polynomials use in the analysis of non-isothermal kinetics. Thermochim. Acta 340: 69-76.

22. Brown ME, Maciejewski M, Vyazovkin S, Nomen R, Sempere J, et al. (2000) Computational aspects of kinetic analysis: part A: the ICTAC kinetics projectdata, methods and results. Thermochim. Acta 355: 125-143.

23. Vyazovkin S (2000) Computational aspects of kinetic analysis.: Part C. The ICTAC Kinetics Project-the light at the end of the tunnel? Thermochim. Acta 355: 155-163

24. Coats AW, Redfern JP (1969) Kinetic Parameters from Thermogravimetric Data Nature (London) 201: 68-69.

25. Ozawa T (1965) Bull Chem Soc Jpn 39: 1881-1886.

26. Ozawa T (1970) Kinetic analysis of derivative curves in thermal analysis J. Thermal Anal 2: 301-324.

27. Vyazovkin S (2001) Modification of the integral isoconversional method to account for variation in the activation energy. J Comput Chem 22: 178-183.

28. Sbirrazzuoli N, Girault Y, Elegant L (1995) Simulations for evaluation of kinetic methods in differential scanning calorimetry. Part 1. Application to single-peak methods. Thermochim Acta 260: 147-164.

29. Sbirrazzuoli N (1996) Simulations for evaluation of kinetic methods in differentia scanning calorimetry. Part 2. Effect of additional noise on single-peak methods. Thermochim Acta 273: 169-184.

30. Sbirrazzuoli N, Girault Y, Elegant $L$ (1997) Simulations for evaluation of kinetic methods in differential scanning calorimetry. Part 3-Peak maximum evolution methods and isoconversional methods. Thermochim Acta 293: 25-37.

31. Sbirrazzuoli $N$ (2007) Is the Friedman method applicable to transformations with temperature dependent reaction heat? Macromol Chem Phys 208: 1592-1597.

32. Perez MLA, Sanchez JPE, Criado JM (2005) Evaluation of the integral methods for the kinetic study of thermally stimulated processes in polymer science. Polymer 46: 2950-2954.

33. Starink MJ (2003) The determination of activation energy from linear heating rate experiments: a comparison of the accuracy of isoconversion methods. Thermochim Acta 404: 163-176.

34. Sbirrazzuoli N, Vincent L, Mija A, Guigo N (2009) Chemom Intell Lab Syst 90 219-226.

35. Vyazovkin SV, Romanovsky IS, Lesnikovich AI (1988) Complementarity methodology as applied for solution of the inverse problem for solid-phase reaction kinetics II Generalized kinetic description using a spectrum of functions. J Thermal Anal 34: 239-247.

36. Criado JM, Dollimore D, Heal GR (1982) A critical study of the suitability of the Freeman and Carroll method for the kinetic analysis of reactions of thermal decomposition of solids. Thermochim Acta 54: 159-165.

37. Ortega A (2002) The kinetics of solid-state reactions toward consensus, Part 
Citation: Guida MY, Bouaik H, El Mouden L, Moubarik A, Aboulkas A, et al. (2017) Utilization of Starink Approach and Avrami Theory to Evaluate the Kinetic Parameters of the Pyrolysis of Olive Mill Solid Waste and Olive Mill Wastewater. J Adv Chem Eng 7: 155. doi: 10.4172/20904568.1000155

2: Fitting kinetics data in dynamic conventional thermal analysis. Int $\mathrm{J}$ Chem Kinet 34: 193-208.

38. Flynn JH, Wall LA (1966) General treatment of the thermogravimetry of polymers. J Res Nat Bur Stand 70: 487-523.

39. Li CR, Tang TB (1997) Dynamic thermal analysis of solid-state reactions. J Thermal Anal 49: 1243-1248.

40. Starink MJ (1996) A new method for the derivation of activation energies from experiments performed at constant heating rate. Thermochim Acta 288: 97-104.

41. Kissinger HE (1957) Reaction kinetics in differential thermal analysis. Anal Chem 29: 1702-1706.

42. Ruitenberg G, Woldt E, Petford-Long AK (2001) Comparing the Johnson-MehlAvrami-Kolmogorov equations for isothermal and linear heating conditions. Thermochim Acta 378: 97-105.

43. Kumar SA, Gupta P, Kumar SR (2009) Modelling of pyrolysis of large wood particles. Bioresour Technol 100: 3134-3139.

44. Ozawa T (1965) A new method of analyzing thermogravimetric data. Bull Chem Soc Jpn 38: 1881-1886.

45. Liu JG, Jiang XM, Zhou LS, Han XX, Cui ZG (2009) Pyrolysis treatment of oil sludge and model-free kinetics analysis. J Hazard Mater 161: 1208-1215.

46. Ghabi C, Benticha $H$, Sassi M (2006) modélisation et simulation numérique de la pyrolyse du noyau d'olive. Afrique science 02: 142-162.

47. Vitolo S, Petarca L, Bresci B (1999) Treatment of olive oil industry waste. Bioressources Technology 67: 129-137.

48. Carrier M, Carrier M, Loppinet SA, Denux D, Lasnier JM, et al. (2011) Thermogravimetric analysis as a new method to determine the lignocellulosic composition of biomass. Biomass and bioenergy 35: 298-307.

49. Font R, Rey MD (2013) Kinetics of olive oil pyrolysis. Journal of analytical and applied pyrolysis 103: 181-188.

50. Paini M, Aliakbarian B, Casazza AA, Lagazzo A (2015) Microencapsulation of phenolic compounds from olive pomace using spray drying : a study of operative parameters. Food science and technology 62: 177-186.

51. Francioso O, Ferrari E, Saladini M, Montecchio D, Gioacchini $P$, et al. (2007) TG-DTA, DRIFT and NMR characterization of humic-like fractions from olive wastes and amended soil. Journal of Hazardous Materials 149: 408-417.

52. Yiliang X, Baoliang $C$ (2013) Investigation of thermodynamic parameters in the pyrolysis conversion of biomass and manure to biochars using thermogravimetric analysis. Bioresource Technology 146: 485-493.

53. Lajili M, Limousy L, Jeguirim M (2014) Physico-chemical properties and thermal degradation characteristics of agropellets from olive mill by-products/sawdust blends. Fuel Processing Technology 126: 215-221.

54. Chao G, Yuping D, Tonghui Z (2013) The kinetic analysis of the pyrolysis of agricultural residue under non-isothermal conditions. Bioresource technology 127: 298-305.

55. Ceylan S, Topcu Y (2014) Pyrolysis kinetics of hazelnut husk using thermogravimetric analysis. Bioressource Technology 156: 182-188.

56. Zhou H, Long YQ, Meng AH, Li QH, Zhang YG (2013) The pyrolysis simulation of five biomass species by hemi-cellulose, cellulose and lignin based on TGA curves. Thermochimica Acta 566: 36-43.

57. Luangkiattikhun P, Tangsathitkulchai C, Tangsathitkulchai M (2008) Nonisothermal analysis of oil-palm solid wastes. Bioresource Technology 99: 986-997.

58. Vega LT, Diaz B, Hernandez ME, May CF, Castro BP, et al. (2015) Thermogravimetric analysis as a rapid and sample method to determine the degradation degree of soy biodiesel. Fuel 156: 158-162.

59. Kwang HK (2014) Analysis of thermal degradation kinetics and carbon structure changes of co-pyrolysis between macadamia nut shell and PET using TGA Energy conversion and management 86: 154-164.

60. Grioui N, Kamel HA, Andr'e ZB, Foued H (2006) Thermogravimetric analysis and kinetics modeling of isothermal carbonization of olive wood in inert atmosphere. Thermochimica Acta 440: 23-30.

61. Guangyong Z, Xian Z, Zuobing X, Fengping Y (2012) Study of cellulose pyrolysis using an in situ visualization technique and thermogravimetric analyzer. Journal of Anal and App Pyrolysis 94: 126-130.

62. Ewa R, Krzysztof B (2011) Thermogravimetric biomass to liquid processes Journal of Kones powertrain and transport. 18: 377-383.

63. Yuan $\mathrm{H}$ (2015) Influences of copper on the pyrolysis process of demineralized wood dust throught thermogravimetric and Py-GC/MS analysis. Jou of Anal and App pyrolysis 112: 325-332.

64. Chen Z, Hu M, Zhu X, Guo D, Liu S, et al. (2015) Characteristics and kinetic study on pyrolysis of five lignocellulosic biomass via thermogravimetric analysis. Bioresource Technology 192: 441-450.

65. Garcia MA, Jose APJ, Francisco SB, Montserrat Z (2015) Determination and comparison of combustion kinetics parameters of agricultural biomass from olive trees. Renewable Energy 83: 897-904.

66. John RG, Alan KB (1997) Pyrolysis decomposition kinetics of cellulose-Based materials by constant heating rate micropyrolysis. Energy and Fuels 11: 88-97.

67. Loannidou O, Jung CG, Zabaniotou A (2011) A thermogravimetric model to predict yield product distribution in pyrolysis of agricultural biomass. Catalysis today 167: 129-134. 